Article

\title{
Alcohol and Difficulty Conceiving in the SUN Cohort: A Nested Case-Control Study
}

\author{
Cristina Lopez-del Burgo ${ }^{1,2,3,4, *}$, Alfredo Gea ${ }^{1,3,4,5}$, Jokin de Irala ${ }^{1,2,3,4}$, \\ Miguel A. Martínez-González ${ }^{1,3,4}$, Jorge E. Chavarro ${ }^{5,6}$ and Estefania Toledo ${ }^{1,3,4}$ \\ ${ }^{1}$ Department of Preventive Medicine and Public Health, School of Medicine, University of Navarra, \\ 31008 Pamplona, Navarra, Spain; E-Mails: ageas@alumni.unav.es (A.G.); jdeirala@ unav.es (J.I.); \\ mamartinez@unav.es (M.A.M.-G.); etoledo@unav.es (E.T.) \\ ${ }^{2}$ Institute for Culture and Society, University of Navarra, 31008 Pamplona, Navarra, Spain \\ ${ }^{3}$ CIBER Fisiopatología de la Obesidad y Nutrición, Instituto de Salud Carlos III, 28029 Madrid, Spain \\ ${ }^{4}$ IdiSNA, Navarra Institute for Health Research, 31008 Pamplona, Navarra, Spain \\ ${ }^{5}$ Department of Epidemiology, Harvard T. H. Chan School of Public Health, 02115 Boston, MA, USA; \\ E-Mail: jchavarr@hsph.harvard.edu \\ ${ }^{6}$ Department of Nutrition, Harvard T. H. Chan School of Public Health, 02115 Boston, MA, USA \\ * Author to whom correspondence should be addressed; E-Mail: cldelburgo@ unav.es; \\ Tel.: +34-948-425600 (ext. 806360); Fax: +34-948-425649.
}

Received: 25 May 2015 / Accepted: 22 July 2015 / Published: 27 July 2015

\begin{abstract}
The role of alcohol on fertility remains unclear. We aimed to investigate the association between alcohol and specific alcoholic beverages consumption and the risk of difficulty getting pregnant. We used a case-control study nested within the Seguimiento Universidad de Navarra (SUN) cohort, a prospective, dynamic and multipurpose cohort of 21,705 Spanish university graduates, followed biennially with mailed questionnaires. We identified 686 case-control pairs, matched for age and time in the cohort. Cases were women reporting difficulty getting pregnant. Controls did not consult due to difficulty conceiving and had at least one child during follow-up. After adjustment for potential confounders, we found no association between self-reported difficulty getting pregnant and the number of alcoholic beverages consumed per week, (Odds Ratio [OR] $>5$ drinks/week $v s$. none $=1.04,95 \%$ Confidence Interval $[\mathrm{CI}]=0.72-1.51)$. No association between types of alcoholic beverage and difficulty conceiving (OR $>5$ drinks of wine/week $v s$. none $=1.16$, $95 \% \mathrm{CI}=0.72-1.88 ; \mathrm{OR}>5$ drinks of beer/week vs. none $=1.06,95 \% \mathrm{CI}=0.82-1.37$; $\mathrm{OR}>5$ drinks of spirits/week $v$. none $=1.24,95 \% \mathrm{CI}=0.84-1.64)$ was observed. In conclusion, we found no association between alcohol intake and risk of consulting a
\end{abstract}


physician due to difficulty conceiving. More studies are needed to clearly elucidate the effects of alcohol intake on women's fertility. In the meantime, recommendations about alcohol intake to couples trying to conceive have to be given cautiously.

Keywords: fertility; nested case-control study; diet; alcohol; wine; beer

\section{Introduction}

It has been estimated that there are approximately 48.5 million infertile couples worldwide [1] with prevalence estimates ranging between $15 \%$ and $30 \%$ of couples [2,3]. Causes of infertility are varied and some of them, such as tubo-peritoneal factors and diminished ovarian reserve, are unmodifiable once identified. While potentially modifiable factors, such as smoking, obesity and underweight, are well-established risk factors for infertility, studies about other modifiable factors, such as diet, exercise, caffeine or alcohol intake, show inconsistent findings [4].

The role of alcohol on fertility, while extensively studied, remains unclear [4], especially on female fertility. In women, several studies observed a direct association between alcohol intake and the risk of infertility [5-9]. However, multiple studies have found no association between alcohol intake and female infertility [7,10-13] and a few studies even suggest a beneficial effect of alcohol on female fertility $[14,15]$. To shed further light on the relationship between alcohol intake and fertility, we investigated this association among female participants of the Seguimiento Universidad de Navarra (SUN) cohort.

\section{Materials and Methods}

\subsection{Study Population}

We conducted a case-control study nested in the SUN cohort. The SUN project started in 1999. It is a dynamic, ongoing and multipurpose prospective cohort of university graduates from all over Spain. Details of the project have been published elsewhere [16]. To date, more than 21,000 participants have been included in the cohort. Participants are followed up biennially with mailed questionnaires about diet, other lifestyle factors and health outcomes such as cardiovascular diseases or difficulty conceiving, among others. The retention rate in the cohort is approximately $92 \%$.

The Institutional Review Board of the University of Navarra approved the study protocol. Voluntary completion of the first self-administrated questionnaire to enter into the SUN cohort was considered to imply informed consent.

For the present analysis, we selected 13,231 women recruited until December 2013. Among them, 8749 were aged 20-40 years and had a minimum follow-up of 2 years and a lag-time period of 9 months. After excluding women who were lost to follow-up $(n=782)$, those with extreme total energy intakes ( $<500$ or $>3500 \mathrm{Kcal} /$ day) [17] $(n=691)$ and those who reported difficulty getting pregnant before study inception (prevalent cases) $(n=75)$, there were 7201 women available for the study. To avoid reverse causality bias, we decided to exclude women who had children when they entered into the cohort 
( $n=1914)$. On the other hand, to assure the fertility of the controls, we excluded those with no children during follow-up ( $n=3583)$.

To identify the cases and the controls for this study, we used the question "Have you consulted a physician because of difficulty getting pregnant?" included in all biennial follow-up questionnaires. Incident cases were women answering affirmatively to this question during follow-up with no children when they entered into the cohort. Controls were women who answered negatively to the above-mentioned question, had no children when they entered into the cohort and had at least one child during follow-up. Cases and controls were matched for age and time at risk using an incidence density sampling approach. Accordingly, we had 686 case-control pairs available for the present analyses. Assuming an expected Odds Ratio (OR) of 1.6 [5], a 15\% exposure probability among controls, a 0.2 correlation of exposure between pairs in the case-control set, and a type 1 error of 0.05 our statistical power was $86 \%$.

\subsection{Exposure Assessment}

Dietary information was collected at baseline through a 136-item food-frequency questionnaire (FFQ) [18]. The FFQ included some questions on alcoholic beverages consumption (red wine, other wine, beer, and spirits). Each item had nine categories of consumption frequency (from never or seldom to six or more times per day). Spanish food composition tables were used to derive the nutrient composition of dietary intake [19]. This FFQ was previously validated for the Spanish population. The correlation coefficient between alcohol intake from the FFQ and from four food records was 0.90 [18]. Participants were classified in 4 groups according to their weekly alcohol intake: abstainers, those who drink 1 or less drinks/week, those who drink more than 1 and less than 5 drinks/week, and those who drink 5 or more drinks/week. The same categories were used to classify participants when exploring the association between consuming different alcoholic beverages (wine, beer and spirits) and difficulty conceiving.

\subsection{Covariate Assessment}

The baseline questionnaire inquired information about socio-demographic, anthropometric, and lifestyle variables, such as age, weight, height, physical activity, smoking status and parity. Weight (in kilograms) was divided by the square of height (in meters) to calculate the body mass index (BMI). Self-reported BMI was validated in a subsample of the cohort [20]. Physical activity was collected through a previously validated questionnaire [21]. Adherence to the Mediterranean dietary pattern was assessed with a score proposed by Trichopoulou et al. [22] but excluding alcohol intake in the calculation of this score to avoid overlapping with the main exposure. It scores positively if consumption of cereals, legumes, fish, fruit and vegetables, and the ratio monounsaturated/polyunsaturated fatty acids is beyond the median. It also scores positively if meat and meat products, and dairy products consumption is below the median. The sum of every point leads to a score that ranges from 0 (minimum adherence) to 8 (maximum adherence).

Questionnaires from the SUN project (in Spanish) are available online (http://www.unav.edu/ departamento/preventiva/sun). 


\subsection{Statistical Analysis}

We used conditional logistic regression models to evaluate the association between categories of weekly alcohol intake and the incidence of difficulty conceiving. We calculated odds ratios (OR) and their $95 \%$ confidence intervals (CI) using abstainers group as the reference category. We fitted a crude model, an age-adjusted model, and a multivariable-adjusted model that included the following potential confounders: $\mathrm{BMI}\left(<18.5, \geqslant 18.5\right.$ to $<25, \geqslant 25$ to $\left.<30, \geqslant 30 \mathrm{~kg} / \mathrm{m}^{2}\right)$, smoking status (current smoker, former smoker, never smoker), leisure-time physical activity (METs-h/week), adherence to the traditional Mediterranean dietary pattern (MDP, 3 categories of adherence), use of vitamin supplements (yes/no). Analyses were also adjusted for total energy intake (Kcal/day). We also conducted tests for linear trend by introducing the number of drinks per week as a continuous variable in the model. All $p$ values were two-tailed ( $p<0.05$ was considered statistically significant).

Analyses were performed with the STATA statistical software package, version 12.2.

\section{Results}

For the present analyses, we included 686 matched case-control pairs (Figure 1).

Baseline characteristics of the cases and the controls are shown in Table 1. There were more current smokers among cases than among controls. Obesity and use of vitamin supplements were more common in cases than in controls. Alcohol intake was low in both groups, especially consumption of spirits; mean alcohol intake was $0.35 \mathrm{~g} /$ day.

We did not find any association between the number of alcoholic beverages consumed per week and self-reported difficulty getting pregnant, even after adjustment for possible confounders such as BMI, smoking habit, physical activity, adherence to the Mediterranean diet, use of vitamin supplements and total energy intake (OR >5 drinks/week vs. none $=1.04,95 \% \mathrm{CI}=0.72-1.51)$ (Table 2).

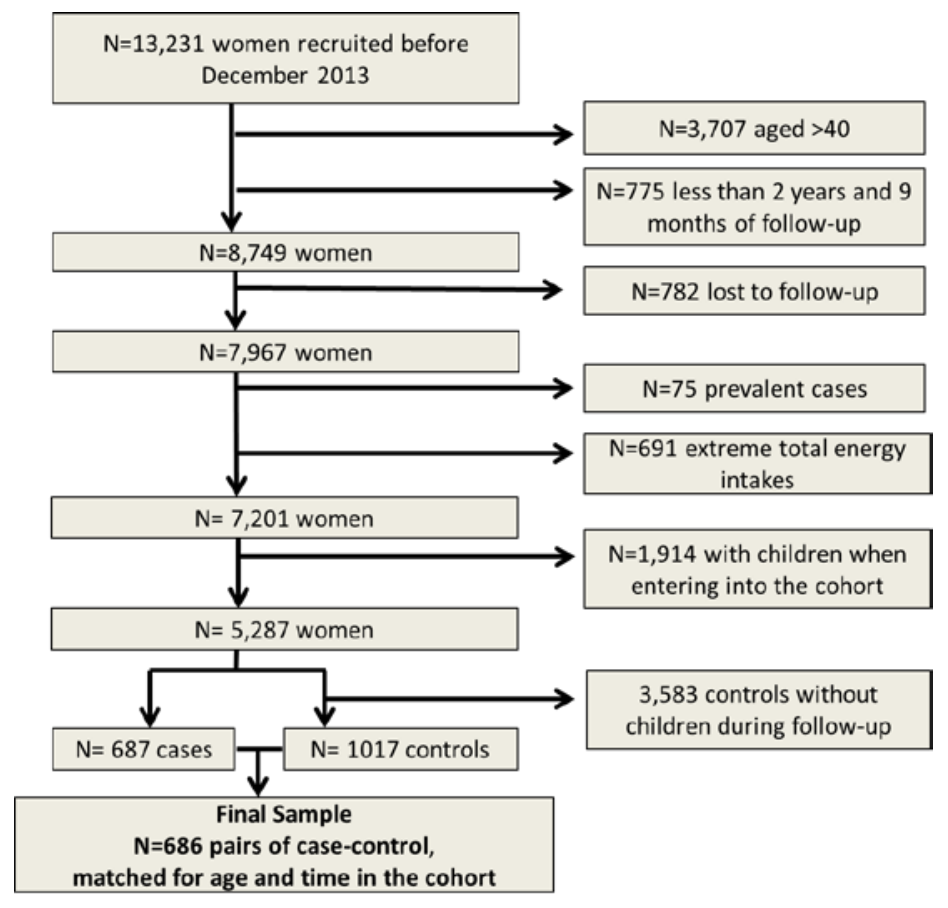

Figure 1. Flow chart of participants in the study 
Table 1. Baseline characteristics of the cases (women with difficulty getting pregnant) and the controls from the Seguimiento Universidad de Navarra (SUN) study, matched for age and time in the cohort.

\begin{tabular}{|c|c|c|}
\hline Baseline Characteristics * & Cases $(n=686)$ & $\begin{array}{l}\text { Matched Controls } \\
\qquad(n=686)\end{array}$ \\
\hline Age, years & $29.3(4.2)$ & $29.3(4.2)$ \\
\hline Body mass index, $\mathrm{kg} / \mathrm{m}^{2}$ & $21.41(2.70)$ & $21.26(2.31)$ \\
\hline \multicolumn{3}{|l|}{ Body mass index, $n(\%)$} \\
\hline$<18.5$ & $56(8.2)$ & $55(8.1)$ \\
\hline$\geqslant 18.5$ to $<25$ & $567(82.6)$ & $589(85.8)$ \\
\hline$\geqslant 25$ to $<30$ & $50(7.3)$ & $36(5.2)$ \\
\hline$\geqslant 30$ & $13(1.9)$ & $6(0.9)$ \\
\hline \multicolumn{3}{|l|}{ Smoking status, $n(\%)$} \\
\hline Never smokers & $363(53.9)$ & $356(53.2)$ \\
\hline Past smokers & 132(19.6) & $204(30.4)$ \\
\hline Current smokers & $179(26.5)$ & $110(16.4)$ \\
\hline Alcohol intake, g/day & $0.35(0.53)$ & $0.36(0.60)$ \\
\hline \multicolumn{3}{|l|}{ Number of alcoholic, drinks/day } \\
\hline Wine & $0.16(0.39)$ & $0.17(0.48)$ \\
\hline Beer & $0.11(0.21)$ & $0.11(0.19)$ \\
\hline Spirits & $0.07(0.14)$ & $0.08(0.15)$ \\
\hline Physical activity, METs-h/week ${ }^{\dagger}$ & $18.7(19.6)$ & $19.1(21.9)$ \\
\hline Adherence to Mediterranean Diet \# & $3.7(1.6)$ & $3.9(1.5)$ \\
\hline Use of vitamin supplements, $n(\%)$ & $134(19.5)$ & $129(18.8)$ \\
\hline Total energy intake, Kcal/day & $2210.6(571.5)$ & $2249.5(546.9)$ \\
\hline
\end{tabular}

* Mean (standard deviation), unless otherwise stated; ${ }^{\dagger}$ METs: ratio of work metabolic rate to a standard resting metabolic rate; $\#$ Adherence to Mediterranean Diet (score from 0, minimum, to 8, maximum).

We also found no association when different alcoholic beverages were analyzed separately, even after adjustment for potential confounders: wine $(\mathrm{OR}>5$ drinks/week $v s$. none $=1.16,95 \% \mathrm{CI}=0.72-1.88)$, beers $(\mathrm{OR}>5$ drinks/week $v s$. none $=1.06,95 \% \mathrm{CI}=0.82-1.37)$ and spirits $(\mathrm{OR}>5$ drinks/week $v s$. none $=1.24,95 \% \mathrm{CI}=0.84-1.64)$. No significant linear trend was observed for any of the alcoholic beverages (Table 2). 
Table 2. Odds ratio (95\% CI) for presenting difficulty getting pregnant according to the consumption of alcoholic beverages/week.

\begin{tabular}{|c|c|c|c|c|c|}
\hline & \multicolumn{4}{|c|}{ Consumption of Alcoholic Beverages (drinks/week) } & \multirow[b]{2}{*}{$P$ for trend } \\
\hline & $\begin{array}{l}\text { Never or } \\
\text { seldom }\end{array}$ & $\leqslant 1 /$ week & $>1$ week to $<5 /$ week & $\geqslant 5 /$ week & \\
\hline No. cases/controls & $152 / 150$ & $154 / 147$ & $284 / 288$ & $96 / 101$ & \\
\hline Matched for age & 1 (ref.) & $1.04(0.75-1.43)$ & $0.97(0.74-1.29)$ & $0.94(0.66-1.34)$ & 0.71 \\
\hline \multirow[t]{3}{*}{ Multivariable adjustment * } & 1 (ref.) & $1.09(0.78-1.53)$ & $1.02(0.76-1.37)$ & $1.04(0.72-1.51)$ & 0.97 \\
\hline & \multicolumn{4}{|c|}{ Consumption of wine $(1$ unit $=1$ glass of wine $=100 \mathrm{~mL}$ ) } & \\
\hline & Never or seldom & $\leqslant 1 /$ week & $>1$ week to $<5 /$ week & $\geqslant 5 /$ week & $P$ for trend \\
\hline No. cases/controls & $312 / 317$ & $177 / 164$ & $156 / 166$ & $41 / 39$ & \\
\hline Matched for age & 1 (ref.) & $1.10(0.84-1.42)$ & $0.95(0.72-1.25)$ & $1.07(0.67-1.70)$ & 0.66 \\
\hline \multirow[t]{3}{*}{ Multivariable adjustment * } & 1 (ref.) & $1.10(0.84-1.43)$ & $0.97(0.74-1.29)$ & $1.16(0.72-1.88)$ & 0.84 \\
\hline & \multicolumn{4}{|c|}{ Consumption of beers ( 1 unit $=330 \mathrm{~mL})$} & \\
\hline & Never or seldom & & & $>1 /$ week & \\
\hline No. cases/controls & $326 / 334$ & & & $208 / 212$ & \\
\hline Matched for age & 1 (ref.) & 1.11 & $-1.45)$ & $1.01(0.78-1.29)$ & 0.71 \\
\hline \multirow[t]{3}{*}{ Multivariable adjustment $*$} & 1 (ref.) & 1.15 & $-1.52)$ & $1.06(0.82-1.37)$ & 0.98 \\
\hline & \multicolumn{4}{|c|}{ Consumption of spirits $(1$ unit $=50 \mathrm{~mL})$} & \\
\hline & Never or seldom & & & $>1 /$ week & \\
\hline No. cases/controls & $377 / 392$ & & & $153 / 140$ & \\
\hline Matched for age & 1 (ref.) & 1.05 & $-1.36)$ & $1.13(0.87-1.47)$ & 0.86 \\
\hline Multivariable adjustment* & 1 (ref.) & 1.11 & $-1.45)$ & $1.24(0.84-1.64)$ & 0.78 \\
\hline
\end{tabular}

* Adjusted for BMI (4 categories), smoking status (3 categories), leisure-time physical activity (METs-h/week), use of vitamin supplements, adherence to the traditional Mediterranean diet and total energy intake. ref.: reference category. 


\section{Discussion}

We prospectively evaluated the relationship between alcohol intake and female fertility, finding no associations between any level of alcohol intake and the risk of consulting a physician due to difficulty conceiving. Neither did we find associations between consumption of different types of alcoholic beverages and this outcome.

Several studies showed a deleterious effect of alcohol on female fertility $[5,6,8,9,23]$, while others did not $[7,10,11,13,14,24,25]$. Inconsistences among studies are expected because several factors have to be taken into account to evaluate the effects of alcohol on fertility-for example, the amount and type of alcoholic beverage consumption, the potential confounders (age, parity, body mass index and lifestyle factors), the definition of the outcome (fecundability, waiting time to pregnancy, infertility due to a specific causes or medical consultation of infertility) and the design of the study and its possible biases [26]. The retrospective data collection may lead to misclassification and thus to biased results.

A case-control study among 4883 women found that moderate and high alcohol intake was associated with infertility due to ovulatory factor and endometriosis [23]. Regarding endometriosis, a frequent cause of infertility, a meta-analysis concluded that there was no association between any level of alcohol intake and endometriosis, although whether alcohol preceded endometriosis or exacerbated it was not clear in this study [24]. In our study, we did not analyze specific causes of infertility.

Another retrospective study evaluated moderate and high alcohol intake and waiting time to pregnancy in a Danish cohort of pregnant women, finding no association between them [14]. Neither did a Canadian study [13]. The European study on infertility and subfecundity, using a multicenter sample of randomly selected women aged 25-44 years, showed no association between alcohol intake and waiting time to pregnancy after adjusting for potential confounders [13].

Besides these, two prospective studies found that increasing alcohol intake was associated with a decrease of fecundability (probability of conception in a menstrual cycle), after adjusting for potential confounders (age, smoking, caffeine intake, etc.). Fecundability was reduced even with low alcohol intake $[8,9]$. It has been proposed that high and moderate intake of alcohol increase sex steroid hormones by stimulating androgen production in ovary and adrenal glands, increasing liver aromatase activity which converts androgens into estrogens or inhibiting liver enzymes to degrade estrogens. The increase in sex steroid hormones reduces FSH secretion and consequently inhibits ovulation [27-29]. However, our findings are not directly comparable to these studies, as our outcome was consulting a physician due to difficulty conceiving, not fecundability.

Another cohort study, conducted in a random sample of 7393 Swedish women, found that high alcohol intake compared to moderate consumers, but not low, was associated with increased risk of having medical examinations due to infertility [5], which was an outcome similar to ours. This inconsistency between Eggert's study and ours could be explained by the fact that the Swedish study only adjusted for age but not for other potential confounders, such as smoking, BMI or parity, as we did. In fact, our results are consistent with other studies [10,11,13,14]. Chavarro et al. followed 18,555 fertile married women in the Nurses' Health Study, measuring dietary factors and other potential confounders. Alcohol drinking was unrelated to ovulatory infertility [10]. This result is not surprising because alcohol may improve insulin sensitivity [30], which is related to a proper ovulatory function [31]. When comparing different alcoholic beverages, wine seemed to have greater beneficial effects on insulin resistance, mainly through 
its non-alcoholic components (the polyphenols) [30,32,33]. However, studies about wine and fertility are really scarce, especially prospective studies. In a retrospective study, Juhl et al. showed a protective effect of wine consumption on shorter waiting times of pregnancy compared with non-wine drinking or other alcoholic drinks [15]. Authors explained that wine drinking is generally associated with healthier lifestyles [34], but they did not control for those factors. In addition, they did not adjust for smoking. Therefore, their results could be biased. More studies evaluating the effect of wine consumption and the Mediterranean alcohol-drinking pattern on fertility are needed.

In our study, several limitations need to be considered. First, we evaluated the association between alcohol intake and difficulty getting pregnant, without specifying causes of infertility. We cannot rule out the possibility that associations with specific conditions in opposite directions could, when aggregated, result in a null finding. Second, we restricted the analysis to women with a university degree that had no children when entering the cohort. Therefore, results could not be generalizable to women with secondary infertility. In any case, the restriction that we applied by selecting only women with a high educational level can actually enhance the internal validity of our results because the high level of education and homogeneity of the cohort also with respect to similar access to health care reduce potential confounding related to socio-economic status. In addition, this characteristic increases the quality of the self-reported information provided by participants. Third, we are aware that characterization of infertility by one question is a crude way to select the targeted population and a non-differential misclassification of the outcome might have happened due to the self-reported nature of the information. But misreporting seems unlikely, as all women in the SUN cohort are highly educated. In fact, several conditions have been validated in this cohort (e.g., depression, metabolic syndrome, hypertension or physical activity), showing high accuracy [21,35-37]. Fourth, alcohol data were obtained from the baseline questionnaire of the SUN study and could have changed thorough the follow-up. In fact, considering that alcohol is a known teratogenic [38,39], many women trying to get pregnant may have avoided taking alcohol all together by the time willing to get pregnant or at least after ovulation. Since the information on alcohol consumption was based on a food-frequency questionnaire and these questionnaires collect the information on the long term, our work reflects the effect of the long-term alcohol consumption rather than a periconceptional short-term effect. Fifth, our questionnaires recall no information on contraceptive use. Thus, we could not take this factor into account as a potential confounder.

Despite these limitations, our study has several strengths. We selected cases and controls with no children when entering into the cohort and chose incident cases to avoid a possible reverse causation bias. It could be argued that nulliparous women might go out more frequently than those having any child, and consequently drink more alcohol, although the opposite could also be possible. In the former situation, infertility would be the "cause" of more alcohol intake instead of the outcome. Selecting nulliparous participants when entering into the cohort and choosing incident cases, as we did, helps to avoid this possible reverse causation bias. Other strengths are data collection and analysis. The high educational level of the participants provides good quality of information and high internal validity. It was also possible to adjust for possible confounders and to assure the fertility of the controls since we excluded those with no children during follow-up. 


\section{Conclusions}

In conclusion, our results showed no association between alcohol intake and the risk of consulting a physician due to difficulty conceiving. Effects of alcohol on infertility deserve further investigation, taking into account that different effects are possible regarding the specific cause of infertility evaluated and the type of alcoholic beverage consumed. More studies are needed to clearly elucidate the effects of alcohol intake on women's fertility. In the meanwhile, recommendations about alcohol intake to couples trying to conceive have to be given cautiously.

\section{Acknowledgments}

We thank participants of the SUN project for their continued cooperation and all members of the SUN project group for their administrative, technical, and material support. The SUN Study has received funding from the Spanish Government (Grants PI01/0619, PI030678, PI040233, PI042241, PI050976, PI070240, PI070312, PI081943, PI080819, PI1002658, PI1002293, RD06/0045, G03/140 and 87/2010), the Navarra Regional Government (36/2001, 43/2002, 41/2005, 36/2008, 45/2011, 27/2011) and the University of Navarra." A. Gea is supported by a FPU fellowship from the Spanish Government.

\section{Author Contributions}

J. de Irala and M.A. Martinez-Gonzalez conceived and designed the study. A. Gea and E. Toledo analyzed the data. C. Lopez-del Burgo wrote the first draft of the manuscript. All authors substantially contributed to the interpretation of results and approved the final version of the manuscript.

\section{Conflicts of Interest}

The authors declare no conflict of interest.

\section{References}

1. Mascarenhas, M.N.; Flaxman, S.R.; Boerma, T.; Vanderpoel, S. Stevens GA National, regional, and global trends in infertility prevalence since 1990: A systematic analysis of 277 health surveys. PLoS Med. 2012, 9, e1001356. [CrossRef] [PubMed]

2. Slama, R.; Hansen, O.K.H.; Ducot, B.; Bohet, A.; Sorensen, D.; Giorgis Allemand, L.; Eijkemans, M.J.C.; Rosetta, L.; Thalabard, J.C.; Keiding, N.; Bouyer, J. Estimation of the frequency of involuntary infertility on a nation-wide basis. Hum. Reprod. 2012, 27, 1489-1498. [CrossRef] [PubMed]

3. Thoma, M.E.; McLain, A.C.; Louis, J.F.; King, R.B.; Trumble, A.C.; Sundaram, R.; Buck Louis, G.M. Prevalence of infertility in the United States as estimated by the current duration approach and a traditional constructed approach. Fertil. Steril. 2013, 99, 1324-1331. [CrossRef] [PubMed]

4. Sharma, R.; Biedenharn, K.R.; Fedor, J.M.; Agarwal, A. Lifestyle factors and reproductive health: Taking control of your fertility. Reprod. Biol. Endocrin. 2013, 11, 66. [CrossRef] [PubMed] 
5. Eggert, J.; Theobald, H.; Engfeldt, P. Effects of alcohol consumption on female fertility during an 18-year period. Fertil. Steril. 2004, 81, 379-383. [CrossRef] [PubMed]

6. Tolstrup, J.S.; Kjaer, S.K.; Holst, C.; Sharif, H.; Munk, C.; Osler, M.; Schmidt, L.; Andersen, A.M.; Gronbaek, M. Alcohol use as predictor for infertility in a representative population of Danish women. Acta Obstet. Gynecol. Scand. 2003, 82, 744-749. [CrossRef] [PubMed]

7. Hassan, M.A.; Killick, S.R. Negative lifestyle is associated with a significant reduction in fecundity. Fertil. Steril. 2004, 81, 384-392. [CrossRef] [PubMed]

8. Jensen, T.K.; Hjollund, N.H.; Henriksen, T.B.; Scheike, T.; Kolstad, H.; Giwercman, A.; Ernst, E.; Bonde, J.P.; Skakkebaek, N.E.; Olsen, J. Does moderate alcohol consumption affect fertility? Follow up study among couples planning first pregnancy. BMJ 1998, 317, 505-510. [CrossRef] [PubMed]

9. Hakim, R.B.; Gray, R.H.; Zacur, H. Alcohol and caffeine consumption and decreased fertility. Fertil. Steril. 1998, 70, 632-637. [CrossRef]

10. Chavarro, J.E.; Rich-Edwards, J.W.; Rosner, B.A.; Willett, W.C. Caffeinated and alcoholic beverage intake in relation to ovulatory disorder infertility. Epidemiology 2009, 20, 374-381. [CrossRef] [PubMed]

11. Curtis, K.M.; Savitz, D.A.; Arbuckle, T.E. Effects of cigarette smoking, caffeine consumption, and alcohol intake on fecundability. Am. J. Epidemiol. 1997, 146, 32-41. [CrossRef] [PubMed]

12. Parazzini, F.; Chatenoud, L.; Di Cintio, E.; La Vecchia, C.; Benzi, G.; Fedele, L. Alcohol consumption is not related to fertility in Italian women. BMJ 1999, 318, 397. [CrossRef] [PubMed]

13. Olsen, J.; Bolumar, F.; Boldsen, J.; Bisanti, L. Does moderate alcohol intake reduce fecundability? A European multicenter study on infertility and subfecundity. European Study Group on Infertility and Subfecundity. Alcohol. Clin. Exp. Res. 1997, 21, 206-212. [CrossRef] [PubMed]

14. Juhl, M.; Nyboe Andersen, A-M.; Grønbæk, M.; Olsen, J. Moderate alcohol consumption and waiting time to pregnancy. Hum. Reprod. 2001, 16, 2705-2709. [CrossRef] [PubMed]

15. Juhl, M.; Olsen, J.; Nybo Andersen, A.M.; Grønbæk, M. Intake of wine, beer and spirits and waiting time to pregnancy. Hum. Reprod. 2003, 18, 1967-1971. [CrossRef] [PubMed]

16. Segui-Gomez, M.; de la Fuente, C.; Vazquez, Z.; de Irala, J.; Martinez-Gonzalez, M.A. Cohort profile: The 'Seguimiento Universidad de Navarra' (SUN) study. Int. J. Epidemiol. 2006, 35, 1417-1422. [CrossRef] [PubMed]

17. Willett, W.C.; Stampfer, M.J. Implications of total energy intake for epidemiologic analyses. In Nutritional Epidemiology; Willett, W.C., Ed.; Oxford University Press: New York, NY, USA, 1998; pp. 273-301.

18. Martin-Moreno, J.M.; Boyle, P.; Gorgojo, L.; Maisonneuve, P.; Fernandez-Rodriguez, J.C.; Salvini, S.; Willett, W.C. Development and validation of a food frequency questionnaire in Spain. Int. J. Epidemiol. 1993, 22, 512-519. [CrossRef] [PubMed]

19. Moreiras, O.; Carbajal, Á.; Cabrera, L.; Cuadrado, C. Tablas de Composición de Alimentos. Pirámide: Madrid, Spain, 2009. 
20. Bes-Rastrollo, M.; Perez Valdivieso, J.R.; Sánchez-Villegas, A.; Alonso, A.; Martinez-Gonzalez, M.A. Validacion del peso e indice de masa corporal auto-declarados de los participantes de una cohorte de graduados universitarios. Rev. Esp. Obes. 2005, 3, 183-189, (In Spanish).

21. Martinez-Gonzalez, M.A.; Lopez-Fontana, C.; Varo, J.J.; Sanchez-Villegas, A.; Martinez, J.A. Validation of the Spanish version of the physical activity questionnaire used in the Nurses' Health Study and the Health Professionals' Follow-up Study. Public Health Nutr. 2005, 8, 920-927. [CrossRef] [PubMed]

22. Trichopoulou, A.; Costacou, T.; Bamia, C.; Trichopoulos, D. Adherence to a Mediterranean diet and survival in a Greek population. New Engl. J. Med. 2003, 348, 2599-2608. [CrossRef] [PubMed]

23. Grodstein, F.; Goldman, M.B.; Cramer, D.W. 1994 Infertility in women and moderate alcohol use. Am. J. Public Health 1994, 84, 1429-1432. [CrossRef] [PubMed]

24. Parazzini, F.; Cipriani, S.; Bravi, F.; Pelucchi, C.; Chiaffarino, F.; Ricci, E.; Viganò, P. A metaanalysis on alcohol consumption and risk of endometriosis. Am. J. Obstet. Gynecol. 2013, 209, 106.e101-106.e110. [CrossRef] [PubMed]

25. Shust, G.F.; Cho, S.; Kim, M.; Madan, R.P.; Guzman, E.M.; Pollack, M.; Epstein, J.; Cohen, H.W.; Keller, M.J.; Herold, B.C. Female genital tract secretions inhibit herpes simplex virus infection: Correlation with soluble mucosal immune mediators and impact of hormonal contraception. Am. J. Reprod. Immunol. 2010, 63, 110-119. [CrossRef] [PubMed]

26. Olsen, J.; Skov, T. Design options and methodological fallacies in the studies of reproductive failures. Environ. Health Persp. 1993, 101 (Suppl. 2), 145-152. [CrossRef]

27. Rinaldi, S.; Peeters, P.H.; Bezemer, I.D.; Dossus, L.; Biessy, C.; Sacerdote, C.; Berrino, F.; Panico, S.; Palli, D.; Tumino, R.; et al. Relationship of alcohol intake and sex steroid concentrations in blood in pre- and post-menopausal women: The European Prospective Investigation into Cancer and Nutrition. Cancer Causes Control 2006, 17, 1033-1043. [CrossRef] [PubMed]

28. Gill, J. The effects of moderate alcohol consumption on female hormone levels and reproductive function. Alcohol. 2000, 35, 417-423. [CrossRef]

29. Eagon, P.K. Alcoholic liver injury: Influence of gender and hormones. World J. Gastroenterol. 2010, 16, 1377-1384. [CrossRef] [PubMed]

30. Wannamethee, S.G.; Camargo, C.A., Jr.; Manson, J.E.; Willett, W.C.; Rimm, E.B. Alcohol drinking patterns and risk of type 2 diabetes mellitus among younger women. Arch. Intern. Med. 2003, 163, 1329-1336. [CrossRef] [PubMed]

31. Azziz, R.; Ehrmann, D.; Legro, R.S.; Whitcomb, R.W.; Hanley, R.; Fereshetian, A.G.; O’Keefe, M.; Ghazzi, M.N. Troglitazone improves ovulation and hirsutism in the polycystic ovary syndrome: A multicenter, double blind, placebo-controlled trial. J. Clin. Endocrinol. MeTable 2001, 86, 1626-1632. [CrossRef]

32. Chiva-Blanch, G.; Urpi-Sarda, M.; Ros, E.; Valderas-Martinez, P.; Casas, R.; Arranz, S.; Guillén, M.; Lamuela-Raventós, R.M.; Llorach, R.; Andres-Lacueva, C.; Estruch, R. Effects of red wine polyphenols and alcohol on glucose metabolism and the lipid profile: A randomized clinical trial. Clin. Nutr. 2013, 32, 200-206. [CrossRef] [PubMed] 
33. Arranz, S.; Chiva-Blanch, G.; Valderas-Martinez, P.; Medina-Remon, A.; Lamuela-Raventos, R.M.; Estruch, R. Wine, beer, alcohol and polyphenols on cardiovascular disease and cancer. Nutrients 2012, 4, 759-781. [CrossRef] [PubMed]

34. Mortensen, E.L.; Jensen, H.H.; Sanders, S.A.; Reinisch, J.M. Better psychological functioning and higher social status may largely explain the apparent health benefits of wine: A study of wine and beer drinking in young Danish adults. Arch. Intern. Med. 2001, 161, 1844-1848. [CrossRef] [PubMed]

35. Alonso, A.; Beunza, J.J.; Delgado-Rodriguez, M.; Martinez-Gonzalez, M.A. Validation of self reported diagnosis of hypertension in a cohort of university graduates in Spain. BMC Public Health 2005, 5, 94. [CrossRef] [PubMed]

36. Fernandez-Montero, A.; Beunza, J.J.; Bes-Rastrollo, M.; Barrio, M.T.; de la Fuente-Arrillaga, C.; Moreno-Galarraga, L.; Martinez-Gonzalez, M.A. Validity of self-reported metabolic syndrome components in a cohort study. Gac Sanit. 2011, 25, 303-307. [PubMed]

37. Sanchez-Villegas, A.; Schlatter, J.; Ortuno, F.; Lahortiga, F.; Pla, J.; Benito, S.; Martinez-Gonzalez, M.A. Validity of a self-reported diagnosis of depression among participants in a cohort study using the Structured Clinical Interview for DSM-IV (SCID-I). BMC Psychiatry 2008, 8, 43. [CrossRef] [PubMed]

38. Riley, E.P.; Infante, M.A.; Warren, K.R. Fetal alcohol spectrum disorders: An overview. Neuropsychol. Rev. 2011, 21, 73-80. [CrossRef] [PubMed]

39. Feldman, H.S.; Jones, K.L.; Lindsay, S.; Slymen, D.; Klonoff-Cohen, H.; Kao, K.; Rao, S.; Chambers, C. Prenatal alcohol exposure patterns and alcohol-related birth defects and growth deficiencies: A prospective study. Alcohol. Clin. Exp. Res. 2012, 36, 670-676. [CrossRef] [PubMed]

(C) 2015 by the authors; licensee MDPI, Basel, Switzerland. This article is an open access article distributed under the terms and conditions of the Creative Commons Attribution license (http://creativecommons.org/licenses/by/4.0/). 